\title{
On the bacterial cell cycle: Escherichia coli mutants with altered ploidy
}

\author{
Nancy J. Trun ${ }^{1}$ and Susan Gottesman \\ Laboratory of Molecular Biology, National Cancer Institute, National Institutes of Health, Bethesda, Maryland 20892 USA
}

\begin{abstract}
We describe a scheme for isolation of new classes of mutants in the cell cycle of Escherichia coli. The mutants were selected as resistant to camphor vapors, which results in increased ploidy, and were subsequently screened for an increase in cell density and an increase in the gene dosage of the lac operon. Our mutations are located at four different places in the chromosome; we have named these loci mbr (moth ball resistant). $m b r A$ maps to $68 \mathrm{~min}$ on the $E$. coli chromosome, $m b r B$ to $88.5 \mathrm{~min}, \mathrm{mbrC}$ to $89.5 \mathrm{~min}$, and $\mathrm{mbrD}$ to $90 \mathrm{~min}$. $\mathrm{mbrD}$ mutations may be alleles of $r p o B$ (a subunit of RNA polymerase). In addition to the selected or screened phenotypes, most of the mutants fail to grow on rich media or at high temperatures. We have examined the nine mutants under nonpermissive conditions, using several techniques to determine the cause of death. We have also coupled our mutations with lesions in $d n a A$, which is required for cell-cycle-specific DNA replication, and $\boldsymbol{m h}$ (the gene for $\mathrm{RNase} H$ ), which is required for specificity in the DNA initiation reaction, and determined the effects of the double and triple mutants under permissive and nonpermissive conditions. These tests have shown that bacteria mutated at mbrA do not tolerate a null mutation in $r n h$, indicating that they are dependent on DNA replication initiating at oriC. In contrast, mutations at $m b r B, m b r C$, and $m b r D$ exhibit their phenotypes independent of oriC initiation of DNA replication, suggesting that the mutations affect factors that influence the DNA/cell ratio regardless of the origin of DNA replication. Based on our results, the mbr mutations appear to have defects in cell-cycle timing and/or defects in chromosomal partitioning.
\end{abstract}

[Key Words: Escherichia coli; altered ploidy; camphor resistance]

Received August 7, 1990; revised version accepted September 12, 1990.

The cell division cycle in Escherichia coli is a carefully controlled series of events, beginning with cell elongation and chromosome replication, followed by chromosome separation, septum formation, and cell separation (for review, see Donachie and Robinson 1987). These events must occur in a precisely timed sequence, as well as in the correct spatial location within the cell. If any single part of the cell cycle fails to occur within these constraints, one or both of the resulting daughter cells could be inviable. In a wild-type $E$. coli, very few inviable daughter cells are produced $\left(\sim 1\right.$ in $10^{-3}$ to $\left.10^{-4}\right)$, indicating that the overall process of cell division is extremely accurate.

At the onset of the division cycle, DNA replication is initiated from a precise location on the chromosome (oriC; for review, see von Meyenburg and Hansen 1987). A major protein involved in determining the frequency of initiation is DnaA (Lobner-Olesen et al. 1989). Various other proteins, including products of many of the dna genes, RNase $\mathrm{H}$, and RNA polymerase, are subsequently needed to complete the initiation process (for review, see von Meyenburg and Hansen 1987). Replication proceeds bidirectionally around the chromosome until it reaches the terminus (terC; Kuempel et al. 1977; Louarn et al. 1977). After it has replicated, the two

${ }^{1}$ Corresponding author. copies of the chromosome must be physically moved toward the two poles of the cell so that the septum can be placed between them. The frequency of septum formation is dependent on the FtsZ protein ( $\mathrm{Bi}$ and Lutkenhaus 1990). Additional proteins (products of the $f t s$ and $p b p$ genes and others) are required for localization and synthesis of the septum and separation of the two daughter cells (for review, see Donachie et al. 1984).

Most of the currently identified cell division mutants were isolated by use of a screen to detect thermosensitive defects that cause cells to filament (Hirota et al. 1968). Whereas this screen has yielded mutations in many different genes, it has failed to uncover several classes, namely chromosomal partitioning defects and mutations altered in coupling of cell-cycle events. Potential partition mutants have been identified by use of screens to detect DNA-less cells (Hiraga et al. 1989). However, it is not clear what role these genes may play in the partition process.

In this paper we describe a scheme for identifying cellcycle mutants that maintain more than the normal number of chromosomes. Our mutants were selected as resistant to camphor vapors, which results in increased ploidy [in E. coli (Ogg and Zelle 1957), in yeasts (Bauch 1941), and in molds (Sansome 1946)]. Subsequently, they were screened for increased density and an increase in the gene dosage of the lac operon. We have identified 
nine mutants, which map to four different chromosomal locations. The mutants have several novel combinations of defects and may represent new classes of cell division mutants in E. coli.

\section{Results}

Rationale for the altered ploidy mutant selection

Because the coupling and spatial constraints of chromosome replication, partitioning of daughter chromosomes, and cell division are so poorly understood, we wished to identify, by mutation, genes that play a role in these processes. The selection that we have employed has the potential to yield several interesting classes of mutations. A collection of altered ploidy mutants should contain (1) mutants in the DNA replication machinery that overinitiate chromosome replication; (2) mutants that have lost the coupling between growth rate and ploidy and thus initiate DNA replication as if they are growing more rapidly than they are; (3) mutants defective in cell division timing such that they have lost the coupling between DNA replication and other cell division events; and (4) mutants defective in chromosomal partitioning. Although each of these classes is defective in a different and discrete step of the cell cycle, all of the mutants could provide useful information on how the events in cell division are choreographed.

\section{Isolation of altered ploidy mutants}

To isolate a collection of altered ploidy mutants, we have taken advantage of an old observation that cells that can grow in the presence of camphor vapors are polyploid. Although the mechanism by which camphor alters the cell is not clear, when bacterial cells are treated with camphor vapors, $\sim 10^{-3}$ to $10^{-4}$ are capable of growth. Most of these cells have an epigenetic change to camphor resistance $\left(\mathrm{Cmr}^{\mathrm{r}}\right)$ that is rapidly lost when the camphor is removed (Ogg and Zelle 1957). Ogg and Zelle have shown that in $E$. coli $\mathrm{B} / \mathrm{r}$, it is possible to isolate a stable heritable mutation that confers $\mathrm{Cmr}^{\mathrm{r}}$ (Ogg and Zelle 1957).

First, we repeated the camphor selection with NT3 (E. coli $\mathrm{K}-12$ ); the frequency of survival is $10^{-3}$ to $10^{-4}$, the same as $E$. coli $\mathrm{B} / \mathrm{r}$. To increase the frequency of stable $\mathrm{Cmr}^{\mathrm{r}}$ mutations, we then mutagenized NT3 with nitrosoguanidine. Twenty-nine stable $\mathrm{Cmr}^{\mathrm{r}}$ mutants, each from a different mutagenized culture, were identified. Because most of the 29 mutants grow more slowly than NT3, they were tested for growth at various temperatures $\left(21,32,37,39\right.$, and $\left.42^{\circ} \mathrm{C}\right)$ on LB, MacConkey, and glucose minimal agar. Thirteen mutants are unable to grow under one or more of these conditions.

If the mutants are accumulating extra chromosomes, they should be more dense than wild-type cells. To test this, we centrifuged the mutant cells in very shallow Percoll gradients (Woldringh et al. 1981). In these gradients, NT3 grown in glucose minimal media (doubling time, $\sim 60-70 \mathrm{~min}$ ) can be separated from NT3 grown in
LB (doubling time, $\sim 20-25 \mathrm{~min}$ ) by at least $15 \mathrm{~mm}$. The 29 mutants were grown to mid-log $\left(\mathrm{OD}_{600}=0.3-0.4\right)$ under permissive conditions and banded in the gradients. Seventeen of the mutants are more dense than NT3, nine are less dense, two have the same density, and one has two populations within it, one slightly denser than NT3 and one much less dense.

One other test we have used to screen the mutants measures the gene dosage of the lac operon. Langridge (1969) reported that the carbon source, lactobionate, is hydrolyzed poorly by $\beta$-galactosidase (product of the lacZ gene) and will not support growth of E. coli. Mutants that have duplicated the wild-type $1 a c Z$ gene are, however, capable of growth on lactobionate as a sole carbon source (Langridge 1969). We determined empirically the concentration of lactobionate needed to support growth of NT441 (NT3 F'lac-pro), yet restrict growth of NT3, and subsequently tested the mutants at this concentration. All of the mutants grow better than NT3 on lactobionate except two of the increased density mutants and one of the less dense mutants.

Based on the tests listed above, nine mutants were chosen for further study. These nine are $\mathrm{Cmr}^{\mathrm{r}}$, have growth defects under one or more conditions, are, except for one, more dense than NT3, and grow better than NT3 on lactobionate as a sole carbon source (for summary, see Table 1). The mutants were named $m b r$ (for moth ball resistant).

\section{Mapping the mbr mutations}

To facilitate mapping, Tn10s linked to $m b r-3, m b r-4$, $m b r-11$, and $m b r-17$ were identified and used to determine whether there is linkage between any of the mutations. The mutations fell into two clusters: $m b r-4$ and $m b r-15$ are linked to the same Tn $10 . m b r-3, m b r-7$, $m b r-11, m b r-17, m b r-18, m b r-19$, and $m b r-20$ are also linked to the same $\operatorname{Tn} 10$ but, based on additional tests, appear to map to different clusters (see below). Hfr matings were used to determine the position on the $E$. coli linkage map (Bachmann 1990) of the Tn10s, and P1 transductions were used to further refine the map position.

The locus at $68 \mathrm{~min}$, designated $\operatorname{mbr} A$ (Fig. $1 \mathrm{~A}$ ), is defined by $m b r-4$, and the Tn 10 linked to this cluster was designated zgi4:: Tn10. mbrA4 exhibits linkage to zgi :: Tn10 (SK2251), zgi4 :: Tn10, and argG. mbr-15 also shows these linkages and may be an allele of $m b r A$.

$m b r B$, as defined by $m b r-20$, is $60 \%$ linked to zij17 :: $\operatorname{Tn} 10$ (the $\operatorname{Tn} 10$ isolated near $m b r-17$ ) but not linked to zja3 :: Tn10 (the $\operatorname{Tn} 10$ near $m b r-3$ ), placing it between 88 and $89 \mathrm{~min}$ (Fig. 1B). $\mathrm{mbrC}$, as defined by $m b r-17$, is close to $b t u B$ at $89.6 \mathrm{~min}$ (Fig. 1B). $m b r-11$ and $m b r-18$ are probably allelic to $m b r C$. $m b r D$, as defined by $m b r-19$, exhibits the same linkage to zij17 :: Tn10 and zja3 :: Tn10 as a Rif mutation in $r p o B$ and shows $<10 \%$ linkage to $b t u B$, indicating that $m b r D$ is located at $90 \mathrm{~min}$ (Fig. 1B). $\mathrm{mbr}-3$ and $\mathrm{mbr}-7$ show the same linkages as mbrD19 and are probably in the same locus. Strains carrying mbrD19 are resistant to rifam- 
Table 1. Initial characterization of the mbr mutations

\begin{tabular}{|c|c|c|c|c|c|}
\hline Mutation & $\mathrm{Map}^{\mathrm{a}}$ & $\mathrm{Cmr} r^{b}$ & Density $^{c}$ & $\mathrm{Lcb}^{d}$ & Phenotypes ${ }^{e}$ \\
\hline Wild type & & - & wt & \pm & \\
\hline Wild-type F'lac & & - & wt & $+++t$ & \\
\hline$m b r A 4$ & $68^{\prime}$ & +++ & heavy & \pm & $\mathrm{LB}^{-} \mathrm{Mac}^{-}$ \\
\hline$m b r A 15$ & $68^{\prime}$ & ++ & wt + light & + & Ts \\
\hline$m b r B 20$ & $88.5^{\prime}$ & + & heavy & + & Ts $\mathbf{L B}^{-} \mathrm{Mac}^{-}$ \\
\hline$m b r C 11$ & $89.5^{\prime}$ & +++ & heavy & +++ & Ts $\mathrm{LB}^{-} \mathrm{Mac}^{-}$ \\
\hline $\mathrm{mbrC17}$ & $89.5^{\prime}$ & ++ & heavy & +++ & Ts $\mathbf{L B}^{-}$ \\
\hline$m b r C 18$ & $89.5^{\prime}$ & ++ & heavy & +++ & Ts \\
\hline$m b r D 3$ & $90^{\prime}$ & +++ & heavy & ++ & Ts $\mathrm{LB}^{-} \mathrm{Mac}^{-}$ \\
\hline$m b r D 7$ & $90^{\prime}$ & ++ & heavy & ++ & Ts $\mathrm{LB}^{-} \mathrm{Mac}^{-}$ \\
\hline$m b r D 19$ & $90^{\prime}$ & ++ & heavy & + & Ts $\mathrm{LB}^{-} \mathrm{Mac}^{-} \mathrm{Rifr}^{\mathrm{r}}$ \\
\hline
\end{tabular}

aMap refers to the location on the E. coli chromosome (Bachmann 1990).

bCmr is growth with camphor. $1+\mid$ Slight growth; $1++\mid$ better growth; $1+++\mid$ growth equal to that of NT3 in the absence of camphor.

'Density refers to relative position in a Percoll gradient. Heavy is more dense than wild type (wt); light is less dense.

${ }^{\mathrm{d}} \mathrm{Lcb}$ refers to growth on lactobionate minimal agar.

e/Ts) Thermosensitive; ( $\left.\mathrm{LB}^{-}\right)$inability to grow on LB agar; ( $\left.\mathrm{Mac}^{-}\right)$inability to grow on MacConkey agar; (Rifr) rifampicin resistant.

picin at all concentrations tested $(25-125 \mu \mathrm{g} / \mathrm{ml})$, whereas all of the other mutants (including those at $m b r A, m b r B$, and $m b r C l$ are sensitive. This suggests that $m b r D 19$ may be an allele of $r p o B$, and because it is

A)



B)

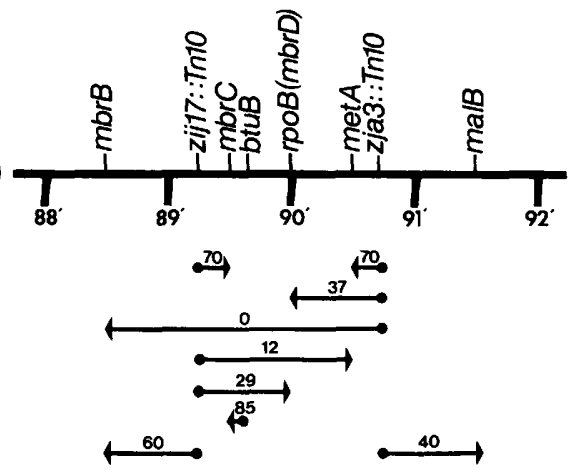

Figure 1. Summary of cotransductional mapping data for $m b r$ mutations. The lines under the maps indicate the two factor crosses that were conducted. The dot on each line indicates the selected marker in the cross; the arrowhead indicates the marker that was counterscreened. The numbers above the lines indicate the cotransductional frequency of the two markers. In all cases, except those with $<$ preceding them, at least 100 transductants (usually 300-500) were checked. $(A)$ The mapping data for $m b r A ;(B)$ the mapping data for $m b r B, \operatorname{mbr} C$, and $m b r D$. in a cluster with $m b r D 3$ and $m b r D 7$, all three may be in rpoB.

\section{Reversion analysis of the mutants}

Using the linked $\operatorname{Tn} 10$ s, the nine mbr mutations were transduced back into NT3 (NT596-NT620). Without exception, all of the phenotypes of the mutations moved together, suggesting that they are the result of a single lesion. As a further test, the mutants were reverted to either growth on $\mathrm{LB}$ or growth at $42^{\circ} \mathrm{C}$. Many of the revertants had changed only the characteristic that was selected. However, with all nine of the mutants, at least one revertant had restored all of the phenotypes to wild type, indicating that a single mutation is responsible for the pleiotropic phenotypes observed in the mutant strains. All subsequent experiments were performed using the strains with the mbr mutations transduced into an unmutagenized NT3 background (NT596NT620).

\section{Reaction of the mutants to nonpermissive conditions}

To investigate the nature of the $m b r$ defects, we wished to determine the reasons that they fail to grow under nonpermissive conditions. The mutants were grown in glucose minimal media to mid-log and subcultured into prewarmed $\mathrm{LB}$ at $37^{\circ} \mathrm{C}$ ( $\mathrm{mbr} A 4, \mathrm{mbrB20}, \mathrm{mbrC11}$, $m b r C 17, m b r D 3, m b r D 7, m b r D 19)$ or prewarmed glucose minimal media at $42^{\circ} \mathrm{C}(\mathrm{mbrA15}, \mathrm{mbrC18})$. At 1 -hr intervals a sample was removed to determine the number of viable cells and the $\mathrm{OD}_{600}$. At 2-hr intervals, samples were stained with the DNA-specific fluorescent dye, 4,6-diamidino-2-phenylindole (DAPI), and viewed in a phase-contrast microscope by use of both UV and visible light sources. The data for $\operatorname{mbr} A 4, \operatorname{mbr} B 20$, $m b r C 17$, and $m b r D 19$ are shown in Figures 2 and 3 . mbra15 behaves essentially like $m b r A 4, m b r C 11$ and mbrC18 behave similiarly to $m b r C 17$, and $m b r D 3$ and 

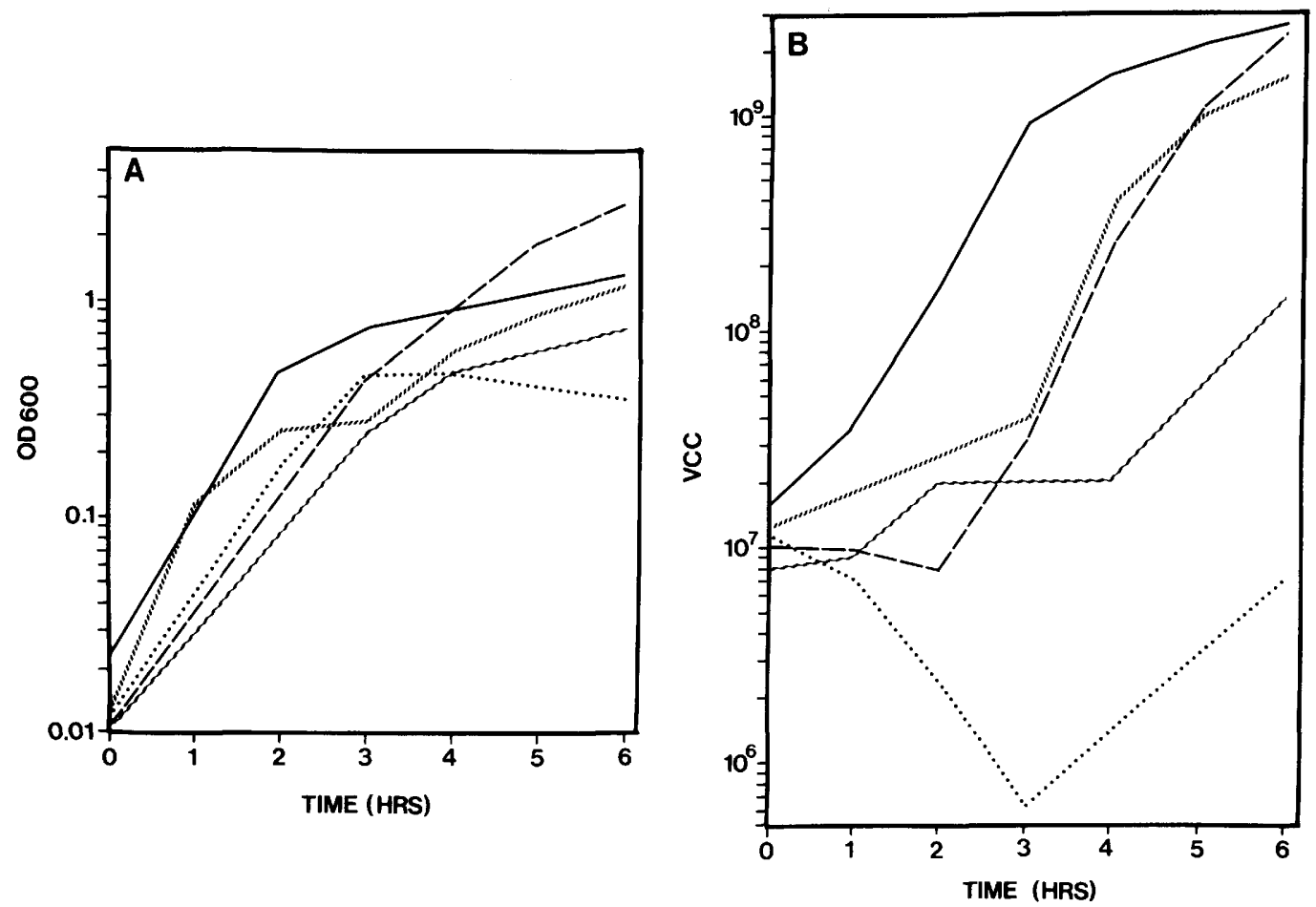

Figure 2. Graphs of optical density vs. time $(A)$ and viable cells per milliliter vs. time $(B)$ of $m b r$ mutants grown in $\mathrm{LB}$ broth at $37^{\circ} \mathrm{C}$. Balanced growth cultures growing in M63 glucose media at $37^{\circ} \mathrm{C}$ were diluted into prewarmed LB at the zero time point. (Solid line) NT597 $\left(\mathrm{mbr}^{+}\right)$; (dashed line) NT604 (mbrA4); (hatched line) NT620 (mbrB20); (dotted line) NT617 (mbrC17); (wavy line) NT619 (mbrD19).

$m b r D 7$ behave identically to $m b r D 19$. As can be seen in Figure $2 \mathrm{~A}$, the $\mathrm{OD}_{600}$ measurements continued to increase under nonpermissive conditions, while the viable cell counts varied widely (Fig. 2B). mbrC17 actually lost viability for the first few hours and subsequently began to grow. $m b r A 4, m b r B 20$, and $m b r D 19$ did not change in cell number for the first few hours but eventually resumed growth. $\operatorname{mbr} A 4, \operatorname{mbr} C 17$, and $m b r D 19$ began to elongate shortly after they were exposed to LB. As the cells filament, the DNA stains as long ribbons that crisscross the cell (Fig. 3, column 2). At the same time the cells exhibited this staining pattern, the viable cell counts indicated that the mutants either lost viability $(m b r C 17)$ or did not increase in number (mbra4, $m b r B 20, m b r D 19)$.

Between 4 and $6 \mathrm{hr}$ after introduction to the nonpermissive conditions, the mutants that did not grow in LB exhibited unusual behavior. The DNA within the filamentous cells began to be divided into visually separate nucleoids (Fig. 3, column 3). After the DNA separated, septation initiated between virtually every nucleoid and the filaments divided en masse, resulting in a large increase in the number of viable cells. Very few of the cells that resulted from division of the filaments were devoid of DNA. If the mutants exposed to LB for $6 \mathrm{hr}$ are reinoculated into LB at low densities, they again exhibit filamentation for the first 4-6 hr, followed by division of the filaments en masse. We do not believe that revertants are overtaking the culture because when the cells that have grown in LB for the viable cell measurements and DAPI stains are streaked on LB agar, they fail to grow. Additionally, if less than $\sim 10^{6}$ mutant cells are inoculated into LB media, they fail to grow, suggesting that they are not capable of the maximal growth rates required for extended growth in LB.

\section{Effects of the mbr mutations with dnaA204(Ts)}

dnaA204(Ts) is a nonreversible temperature-sensitive mutation in $d n a A$ that blocks initiation of replication at the nonpermissive temperature (above $37^{\circ} \mathrm{C}$; Hansen et al. 1984). We combined this lesion in $d n a A$ with the $m b r$ mutations for several reasons. First, mutations that suppress $d n a A(T s$ ) lesions have been identified [sdr (Kogoma and von Meyenburg 1983) and das (Atlung 1981)]. Both $s d r$ and das are alleles of $r n h$ (see below). In these mutants DNA replication is no longer coupled to the cell division cycle. We wished to determine whether any of the mbr mutants are similiar to these suppressors of dnaA204(Ts). Second, we wished to know the effects of blocking chromosome replication from oriC on the $\mathrm{mbr}$ mutants. If the mbr mutants require the normal, cellcycle-controlled replication from oriC for $\mathrm{Cmr}^{\mathrm{r}}$ or filamentation at the nonpermissive conditions, then blocking this replication should prevent the visualization of these defects. If, however, the $m b r$ lesions bypass this replication or exert their effects indirectly, blocking replication from oriC should have no effect. 
Figure 3. Photomicrographs of DAPI-stained cells grown in M63 glucose media (column 1, minimal) at $37^{\circ} \mathrm{C}$ or LB broth for $4 \mathrm{hr}$ (column 2, rich $4 \mathrm{hr}$ ) or $6 \mathrm{hr}$ (column 3, rich $6 \mathrm{hr}$ ) at $37^{\circ} \mathrm{C}$. (Row 1) Wild-type cells (NT597); (row 2) mbrA4 (NT604); (row 3) mbrB20 (NT620); (row 4) mbrC17 (NT617); (row 5) mbrD19 (NT619).

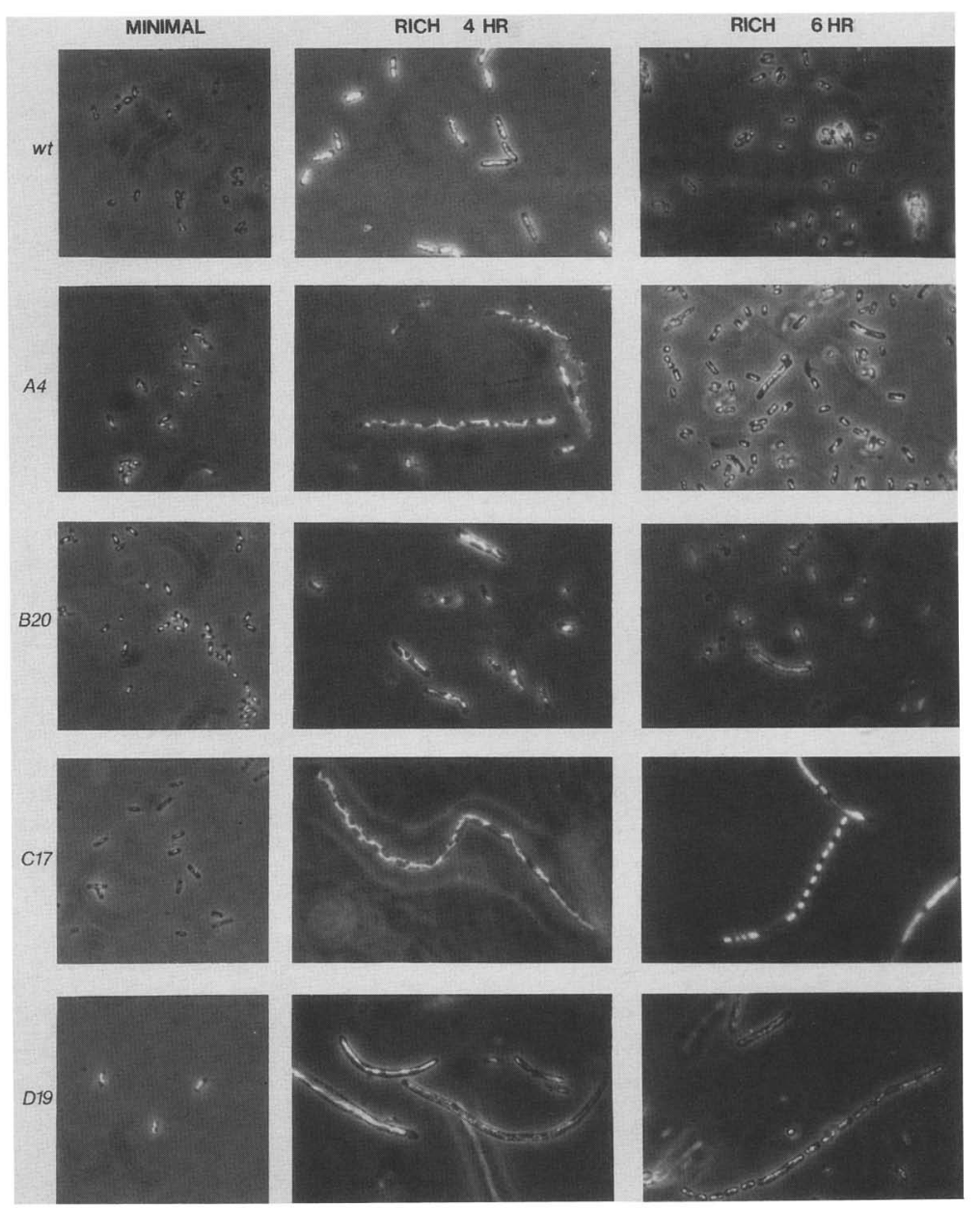

The most striking effect of dnaA204(Ts) is that it blocks resistance to camphor in all of the mbr mutants. This indicates that the extra DNA replication that is responsible for the increased ploidy is DnaA-dependent, most likely originating at oriC. Under nonpermissive conditions, all of the double mutants exhibited the growth defects of both the $m b r$ mutation and dnaA204(Ts) (Table 2). Thus, the mbr mutations do not suppress $d n a A 204$ (Ts) and vice versa. These results indicate that none of the mbr mutations are equivalent to $s d r$ or das.

Figure 4, column 2, shows the DNA-staining phenotypes of some of the double mutants at the nonpermissive conditions. The double mutants have DNA-staining patterns similiar to dnaA204(Ts), indicating that DNA replication is required for the formation of the characteristic long ribbons of DNA seen in the elongated $m b r$ mutant cells.

\section{Effects of the mbr mutations with $\operatorname{mnh} 339$ :: cat}

RNase $\mathrm{H}$, the product of the $r n h$ gene, is required for the cell to initiate DNA replication specifically at oriC. In the absence of RNase $\mathrm{H}$, initiation of DNA replication occurs at oriC, as well as alternate origins, collectively called oriK. Replication from oriK is not cell cycle regulated, occurs in the absence of protein synthesis, and does not require DnaA (Ogawa et al. 1984). In an $\mathrm{nh}^{-}$ strain, $d n a A$ is no longer an essential gene (Kogoma and von Meyenburg 1983). To determine the effects of altering the origin of replication on the mbr mutations, we first transduced rnh339:: cat into strains carrying the mutations and checked the growth defect phenotypes, $\mathrm{Cmr}^{\mathrm{r}}$ (Table 2), and DAPI staining patterns at the permissive and nonpermissive conditions (Fig. 4, column 3).

When the null mutation $\operatorname{rnh} 339$ :: cat was combined with the alleles of $m b r B, m b r C$, and $m b r D$, the strains still exhibited essentially all of the phenotypes of the mbr mutations (Table 2). The DAPI staining of the double mutants indicated that the cell size is somewhat increased under all conditions (Fig. 4, column 3). Thus, allowing initiation of replication from alternate origins does not significantly affect these mutants, indicating that $m b r B, m b r C$, and $m b r D$ are not specific for oriC-dependent replication. When mbrA15 is combined with rnh339:: cat, the double mutant exhibits the phenotypes of mbrA15. However, when $\operatorname{mhh} 339::$ cat is transduced into an mbra4-containing strain, the cells exhibit several novel phenotypes. The most obvious defect is that the double mutant fails to form single colonies on 
Table 2. Phenotypes of mbr mutations with dnaA204(Ts) and $\operatorname{mh} 339$ :: cat

\begin{tabular}{|c|c|c|c|c|c|c|c|c|c|c|c|c|c|c|c|c|}
\hline \multirow[b]{2}{*}{ Mutation } & \multirow[b]{2}{*}{$\mathrm{C}^{\mathrm{a}}$} & \multirow[b]{2}{*}{$M^{a}$} & \multirow[b]{2}{*}{$\mathrm{L}^{\mathbf{a}}$} & \multirow[b]{2}{*}{$\mathrm{T}^{\mathrm{a}}$} & \multicolumn{4}{|c|}{$d n a A 204(T s)^{\mathbf{a}}$} & \multicolumn{4}{|c|}{$m h 339:: c a t^{\mathbf{a}}$} & \multicolumn{4}{|c|}{$\begin{array}{c}\text { dnaA204(Ts) } \\
\text { rnh339:: cat }\end{array}$} \\
\hline & & & & & $\mathrm{C}$ & $\bar{M}$ & $\mathrm{~L}$ & $\bar{T}$ & $\mathrm{C}$ & $M$ & $\mathrm{~L}$ & $\bar{T}$ & $\mathrm{C}$ & $M$ & $\mathrm{~L}$ & $\overline{\mathrm{T}}$ \\
\hline$m b r A 4$ & $\mathrm{R}$ & - & - & $\mathrm{R}$ & $\mathrm{S}$ & - & - & $\mathrm{S}$ & $\mathrm{S}$ & - & - & $\mathrm{S}$ & $\mathrm{S}$ & - & - & $\bar{S}$ \\
\hline$m b r A 15$ & $\mathbf{R}$ & + & + & $\mathrm{S}$ & $S$ & + & + & $\mathrm{S}$ & $\mathrm{R}$ & + & + & $\mathrm{S}$ & $\mathrm{S}$ & + & + & $\mathrm{R}$ \\
\hline$m b r B 20$ & $\mathrm{R}$ & - & - & $\mathrm{S}$ & $\mathrm{S}$ & - & - & $\mathrm{S}$ & $\mathrm{R}$ & - & - & $S$ & $\mathrm{R}$ & - & - & $\mathrm{S}$ \\
\hline$m b r C 11$ & $\mathrm{R}$ & - & - & $\mathrm{S}$ & $S$ & - & - & $\mathrm{S}$ & $\mathrm{R}$ & - & - & $\mathrm{S}$ & $\mathrm{R}$ & - & - & $\mathrm{S}$ \\
\hline$m b r C 17$ & $\mathbf{R}$ & + & - & $\mathrm{S}$ & $S$ & + & - & $\mathrm{S}$ & $\mathrm{R}$ & - & - & $S$ & $\mathbf{R}$ & - & - & $\mathrm{S}$ \\
\hline$m b r C 18$ & $\mathrm{R}$ & + & + & $\mathrm{S}$ & $\mathrm{S}$ & + & + & $\mathrm{S}$ & $\mathrm{R}$ & + & + & $S$ & $\mathrm{R}$ & - & - & $\mathrm{S}$ \\
\hline$m b r D 3$ & $\mathrm{R}$ & - & - & $\mathrm{S}$ & $\mathrm{S}$ & - & - & $\mathrm{S}$ & $\mathrm{R}$ & - & - & $S$ & $\mathrm{R}$ & - & - & $\mathrm{S}$ \\
\hline$m b r D 7$ & $\mathrm{R}$ & - & - & $\mathrm{S}$ & $S$ & - & - & $\mathrm{S}$ & $\mathrm{R}$ & - & - & $S$ & $\mathrm{R}$ & - & - & $\mathrm{S}$ \\
\hline$m b r D 19$ & $\mathrm{R}$ & - & - & $\mathrm{S}$ & $\mathrm{S}$ & - & - & $\mathrm{S}$ & $\mathrm{R}$ & - & - & $S$ & $\mathrm{R}$ & - & - & $S$ \\
\hline NT3 & $\mathrm{S}$ & + & + & $\mathrm{R}$ & $\mathrm{S}$ & + & + & $\mathrm{S}$ & $\mathrm{S}$ & + & + & $\mathrm{R}$ & $S$ & + & + & $\mathrm{R}$ \\
\hline
\end{tabular}

(C) Sensitivity or resistance to the presence of camphor vapors at 32 and $37^{\circ} \mathrm{C} ;(\mathrm{M})$ growth on MacConkey agar at 32 and $37^{\circ} \mathrm{C} ;(\mathrm{L})$ growth on $\mathrm{LB}$ agar at 32 and $37^{\circ} \mathrm{C} ;(\mathrm{T})$ sensitivity or resistance to growth at $42^{\circ} \mathrm{C}$.

a(R) Resistance; (S) sensitivity; (- | no growth; |+ | growth.

glucose minimal agar at $32^{\circ} \mathrm{C}$ (a condition permissive for each of the mutations separately); the double mutant will only grow in the heavy part of the streak on minimal or rich agar at $23,32,37,39$, or $42^{\circ} \mathrm{C}$. The DAPI staining pattern of the double mutant indicated that the cells vary widely in cell length and DNA content, with many of the cells forming very long filaments with the DNA in a novel spiraled pattern (Fig. 4, column 3).

Effects of mbr mutations with dnaA204(Ts) and $\operatorname{rnh} 339::$ cat

To determine the effects of completely blocking oriCdependent replication and demanding that the cells use only the alternate origins, we have combined the $m b r$ mutations with both dnaA204(Ts) and rnh339 :: cat. If the polyploidy of the $m b r$ mutants does not depend on oriC-initiated replication, the triple mutants should be Cmr because dnaA204(Ts) is silent in the rnh339:: cat background. If, however, the polyploidy of the mutants requires initiation of DNA replication from oriC, eliminating it should mask the mbr defects and the triple mutants should be camphor sensitive.

Addition of the $r n h$ null mutation to strains carrying $m b r B, m b r C$, and $m b r D$ restores $\mathrm{Cmr}^{\mathrm{r}}$, suggesting that the triple mutants are again polyploid. Thus, these mutants affect factors that influence the DNA/cell ratio regardless of the origin of DNA replication. These triple mutants retain the growth defects characteristic of the $m b r$ mutations, and in some cases, notably $m b r C 17$ and $m b r C 18$, additional growth defects are seen in the presence of $r n h 339::$ cat (Table 2). mbrA4 again exhibits severe growth defects in the presence of the $r n h$ mutation, and for both mbrA4 and mbrA15, rnh339:: cat does not restore $\mathrm{Cmr}^{\mathrm{r}}$. These results suggest that the mutations at $m b r A$ require DNA replication to initiate at oriC to exhibit $\mathrm{Cmr}^{\mathrm{r}}$ and are unable to tolerate cell cycle independent replication initiation.

\section{Discussion}

Growth in the presence of camphor vapors: the mbr mutants

Beginning with slowly growing cells, we have isolated nine mutants with altered ploidy by selecting for growth in the presence of camphor vapors. Very few of the genes known to play a role in DNA replication and cell division were identified by the $\mathrm{Cmr}^{\mathrm{r}}$ selection, implying that overinitiating replication or slowing septation is not enough to allow the cells to survive this selection. Although the mechanism of $\mathrm{Cmr}^{\mathrm{r}}$ is unknown, it is clear that it selects for a novel class of mutants with cell cycle defects, termed $m b r$. The $\mathrm{Cmr}^{\mathrm{r}}$ mutants map to four chromosomal locations: $\mathrm{mbrA}$ at $68 \mathrm{~min} ; \mathrm{mbrB}$ at 88.5 min; $m b r C$ at $89.5 \mathrm{~min}$; and $m b r D$ at $90 \mathrm{~min}$. $m b r A$, $m b r B$, and $m b r C$ define either new genes or genes not previously implicated in the cell cycle. The mutations at $68 \mathrm{~min}(\mathrm{mbrA})$ may define a gene analogous to the $E$. coli B lar gene, which also maps to $68 \mathrm{~min}$ and has the phenotypes of resistance to camphor and increased cell size and DNA content (Ogg and Zelle 1957; Kvetkas et al. 1970). $m b r D$ appears to be allelic to $r p o B$.

\section{Increased ploidy in the mbr mutants}

The $\mathrm{Cmr}^{\mathrm{r}}$ of the mbr mutants is reversed by introducing a $\operatorname{dnaA}(T s)$ mutation and restored in most of the mutants $(m b r B, m b r C$, and $m b r D)$ when a mutation defective in RNase $\mathrm{H}$ is added to the $m b r$ dnaA(Ts) cells. The loss of $\mathrm{Cmr}^{\mathrm{r}}$ in all of the $\mathrm{mbr} d n a A(T s)$ strains supports the idea that $\mathrm{Cmr}^{\mathrm{r}}$ reflects increased ploidy. When replication initiation is compromised as it is in the $\operatorname{dnaA}(T s)$ even at permissive temperatures (von Meyenburg and Hansen 1987), the extra DNA and, therefore, the Cmr of the $m b r$ strains, is lost. This also implies that the increased ploidy of $m b r$ is normally $d n a A$-dependent, initiated at oriC.

Bypassing oriC and allowing secondary origins to ini- 
Figure 4. Photomicrographs of single, double, and triple mutant combinations of $m b r$, dnaA204(Ts), and mh339:: cat incubated at the nonpermissive conditions. (Column 1) $\mathrm{mbr}$ single mutants (dna $\mathrm{A}^{+}$ $\mathrm{rnh}^{+} \mid$exposed to $\mathrm{LB}$ broth at $37^{\circ} \mathrm{C}$ for $4 \mathrm{hr}$; (column 2) mbr dnaA204(Ts) exposed to LB broth at $42^{\circ} \mathrm{C}$ for $2 \mathrm{hr}$ (DAPI-stained cells from the 2- and 4-hr time points appeared identical); (column 3) mbr rnh339:: cat exposed to $\mathrm{LB}$ broth at $37^{\circ} \mathrm{C}$ for $4 \mathrm{hr}$; (column 4) triple mutants [mbr dnaA204(Ts) rnh339:: cat l exposed to LB broth at $37^{\circ} \mathrm{C}$ for $4 \mathrm{hr}$. (Row 1) $\mathrm{mbr}^{+}$; (row 2) $\mathrm{mbrA4}$; (row 3) mbrB20; (row 4) mbrC17; (row 5) mbrD19.

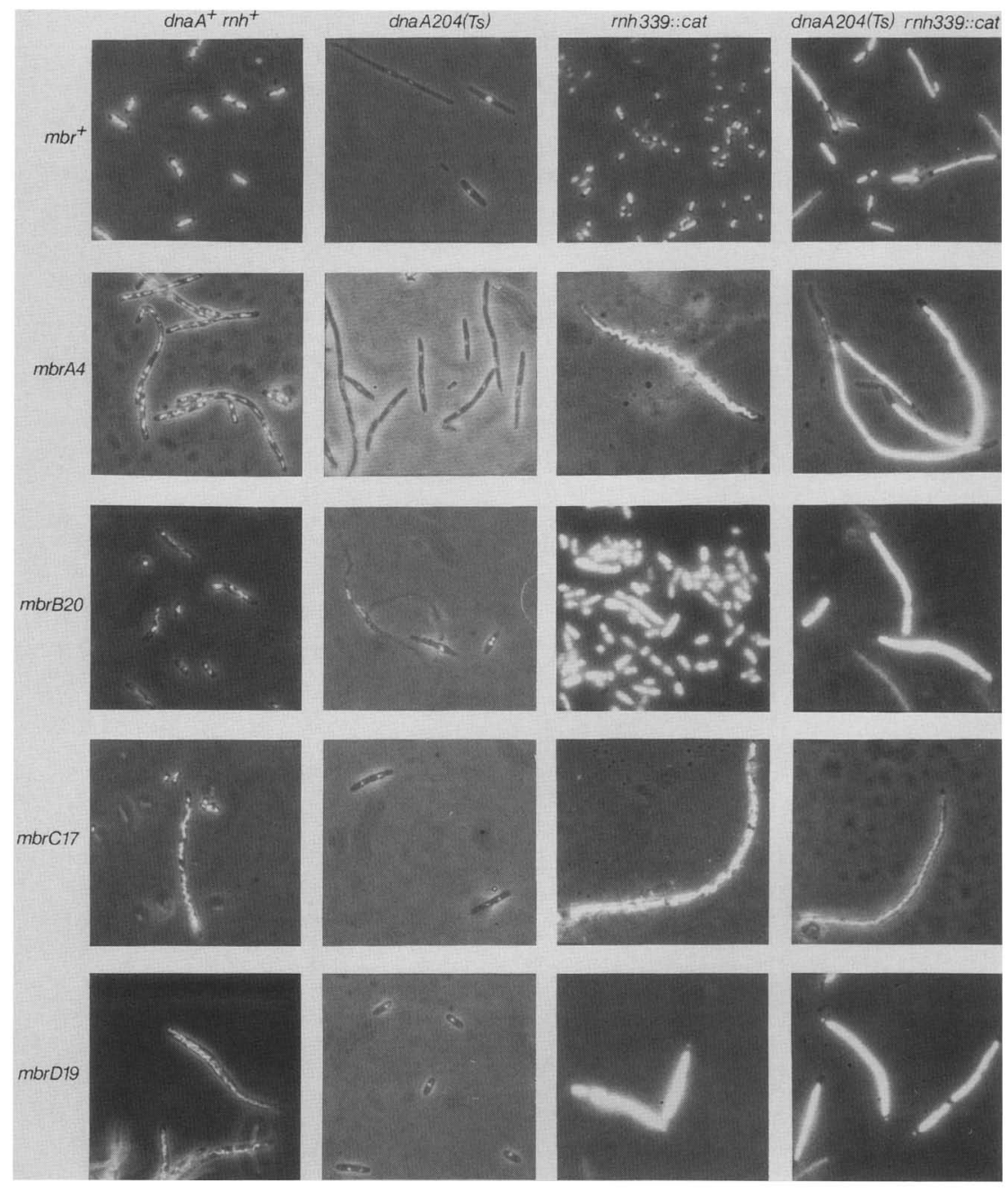

tiate is not sufficient to increase ploidy and make cells $\mathrm{Cmr}^{\mathrm{r}}$, since neither an $\mathrm{rnh}$ single mutant nor an $\mathrm{rnh}$ dnaA double mutant is $\mathrm{Cmr}$. Finally, the $r n h$ mutant allows the strains carrying $m b r B, m b r C$, and $m b r D$ in combination with $d n a A(T s)$ to initiate replication at origins other than oriC and simultaneously restores $\mathrm{Cmr}^{\mathrm{r}}$. Therefore, the defect that increases ploidy in these mutants requires DNA replication but can function independently of oriC.

\section{E. coli cell cycle}

Under nonpermissive conditions, the $m b r$ mutants are capable of undergoing a complete cell cycle but with abnormal timing of the cycle relative to wild-type strains. Instead of doubling at 20- to 30-min intervals in LB, the mutants divide every $4-6 \mathrm{hr}$. When the filaments produced at the nonpermissive conditions do divide, very few of the resulting cells are devoid of DNA. Thus, in the $m b r$ mutants, division is delayed until every future cell has been partitioned a chromosome. These two striking characteristics of the mutants, in combination with the results from the $d n a A(T s)$ and $\mathrm{rnh}^{-}$experi- ments, allow us to make a preliminary placement of the $m b r$ defects within the context of the normal cell cycle.

Figure 5 summarizes the interrelationships of many of the key events in the timing of the $E$. coli cell cycle. The genes known to be required to complete most of these stages, as well as those genes involved in determining the location of each process, have not been listed (for reviews, see Donachie et al. 1984; von Meyenburg and Hansen 1987). Bernander and Nordstrom (1990) have proposed that the chromosome replication and cell division cycles run in parallel but independently of one another. To ensure productive cell duplication, both cycles must be connected at specific points.

The cell division cycle (Fig. 5, outer circle) begins with newly separated daughter cells. The newborn cells elongate until they have reached twice their initial length, whereupon they initiate formation of the septum in the middle of the long axis of the cell. After the septum has formed, the two daughter cells are separated and the cycle begins again (for review, see Donachie and Robinson 1987).

At a specific cell mass, termed the initiation mass $\left(M_{i}\right)$, DNA replication is initiated from oriC (Donachie 




Figure 5. Interrelationships of many of the key events in the timing of the E. coli cell cycle. The outer circle shows the cell division cycle; the inner half circle shows the DNA replication pathway; the inner dashed half circle shows the proposed chromosome partition pathway. Hashed lines depict the preliminary placement of the $m b r$ mutants in the cell cycle. (For additional details, see text.)

1968). DnaA is responsible for sensing $M_{i}$ and, accompanied by protein and RNA synthesis, initiating replication (Fig. 5, inner solid line; Lobner-Olesen et al. 1989). It has been shown that replication of the entire chromosome requires at least $40 \mathrm{~min}$ (Cooper and Helmstetter 1968). When a cell is dividing every $20 \mathrm{~min}$, it must initiate multiple rounds of DNA replication within one cell division cycle. Thus, the level of initiation of DNA replication must be coupled to the growth rate of the cells.

The phenotypes of the $m b r B$ mutant indicate that it may be defective in this coupling of growth rate and DNA replication. At the permissive conditions, $m b r B$ is increased in ploidy, is uniform in cell size, and has a uniformly high density. At the nonpermissive conditions, the mutant exhibits a wide range of cell sizes that vary in their DNA content. This suggests that in minimal media, the $m b r B$ mutant is growing as if it were in rich media, and upon the shift to LB, the mutant cannot keep the cell cycle coordinated with the growth rate. If the increased ploidy at the permissive conditions were simply due to extra initiations per cell, the phenotypes of $m b r B$ should be dependent on the presence of $d n a A$; this is clearly not the case. The fact that the $m b r B$ mutant phenotypes can be seen when DNA replication is initiated at several different origins indicates that the defect in $m b r B$ is not specific for any particular origin of replication. These results lead to the speculation that a factor needed for DNA replication at both oriC and oriK (perhaps an initiation factor) is regulated by growth rate, and in the mbrB mutant this factor (MbrB itself?) is present in elevated levels.

In a mutant deficient in RNase $\mathrm{H}\left(\mathrm{rnh}^{-}\right)$, a mechanism that allows stable DNA replication (SDR) is activated (Fig. 5, inner solid line; Kogoma and Lark 1975). SDR is characterized by a lack of a requirement for protein synthesis and DNA replication that initiates at origins (collectively called oriK) other than oriC (Kogoma and von Meyenburg 1983; deMassy et al. 1984). These initiation events occur randomly throughout the cell cycle and are thus insensitive to $M_{i}$ (von Meyenburg and Hansen 1987).

When excess DnaA is supplied from a plasmid, multiple replication forks are started. The excess forks do not traverse the entire chromosome, however, indicating that they are stalled or aborted (Atlung et al. 1987). This implies that there is an additional level of control responsible for keeping the number of replicating forks coordinated with the cell division cycle and growth rate of the cells.

The phenotypes of the mbrA mutants suggest that this gene may define a new mechanism that couples the DNA replication and cell division cycle. At the permissive conditions, both $m b r A$ alleles show an increase in ploidy and uniform cell size. mbrA4 has a uniform increase in density, whereas $m b r A 15$ has two distinct populations, one slightly more dense than wild type and one much less dense. Both alleles require $d n a A^{+}$to be $\mathrm{Cmr}^{r}$, and $m b r A 4$ cannot tolerate $r n h^{-}$and the activation of oriK. It is clear that initiation of DNA replication in a $d n a A^{+}$strain is tied to the cell cycle through $\mathrm{M}_{\mathrm{i}}$. If this were the only connection, an $r n h^{-}$mutant that bypasses $\mathrm{M}_{\mathrm{i}}$ should have completely uncoupled DNA replication from the cell cycle, and the prediction is that an $\mathrm{Anh}^{-}$ mutant should produce a large number of DNA-less cells, as well as cells with widely varying DNA contents. Because $r n h^{-}$cells appear to be uniform in cell size and DNA content (Fig. 4), this suggests that DNA replication is still coupled to the cell division cycle by a second level of control. If the mbra mutants are defective in this second level of control, their only coordination between DNA replication and cell division would be through $d n a A$ and $\mathrm{M}_{\mathrm{i}}$ eliminating $d n a A$ would completely uncouple DNA replication and cell division. This would explain the dependence of $m b r A$ on the presence of $d n a A$ and the inability of the $m b r A 4, \mathrm{rnh}^{-}$ double mutant to grow at any appreciable rate. We show this new coupling tentatively in Figure 5, located beyond initiation of DNA replication but before termination of chromosome replication.

When oriC has been replicated, the newly synthesized strand remains unmethylated for a longer period of time than other newly replicated DNA (Campbell and Kleckner 1990). Ogden et al. (1988) have shown that hemimethylated oriC binds specifically to two membrane proteins and have proposed that this binding may be intimately involved in chromosomal partitioning. Additional evidence suggests that chromosomal partitioning occurs concomitantly with DNA replication 
(Woldringh 1976). Very little is known about partitioning of oriK-initiated DNA replication.

DNA replication proceeds bidirectionally from oriC (or oriK) around the chromosome until the forks reach ter $C$, where replication stops and the chromosomes separate completely from one another (Kuempel et al. 1977; Louarn et al. 1977). terC is dispensable. In its absence, chromosome segregation still occurs (Henson et al. 1984). The mechanism by which segregation takes place in the terC deletion and in wild-type cells remains to be elucidated.

The phenotypes of the $m b r C$ mutations suggest that they may be defective in chromosomal partitioning or in the coupling of partitioning to the cell division cycle. At the permissive conditions, the mutants are increased in cell length and ploidy. The increase in ploidy does not depend on $d n a A$. At the nonpermissive conditions, the mutants form very long filaments with the DNA in a novel ribbon-like structure that crisscrosses the cell. Before the filaments begin to divide, the DNA ribbon is separated into discrete nucleoids and segregated into distinct sections of the filaments. These results suggest that the $m b r C$ mutations are slowed in chromosomal segregation. However, given enough time, the mutant cells can move the chromosomes apart.

The phenotypes of the mbrD mutations are similiar to those of $m b r C$. At the permissive conditions, the mutants are uniform in cell length and increased in ploidy in a dna $A$-independent manner. At the nonpermissive conditions, the mutants form long filaments of DNA that must be divided into discrete nucleoids before the filaments can septate. $m b r D$ is probably allelic to $r p o B$; increased ploidy mutants have been identified previously in rрoB (Rasmussen et al. 1983; Tanaka et al. 1983). It is known that RNA synthesis is required for initiation of DNA replication (Lark 1972) and protein synthesis is required for initiation of DNA replication and between termination of DNA replication and initiation of septation (Donachie and Begg 1989b). Because $m b r C$ and $m b r D$ mutants are similiar in appearance, they might be defective in similiar steps. It is also possible that $m b r D$ mutations are defective in expression of a specific gene or genes. Our alleles of $r p o B$ fail to grow on rich media, MacConkey media, and at high temperatures, which makes them different from any previously isolated $r p o B$ mutants. The $m b r D$ alleles may provide a way to examine the role of RNA polymerase in different parts of the cell cycle.

The completion of chromosome segregation is thought to be tied to the cell division cycle in at least two manners. The presence of DNA (unseparated chromosomes) in the center of the cell, where the septum initiates, has been proposed to prevent the septum from forming (Mulder and Woldringh 1989). Additionally, both chromosome separation and initiation of septum formation appear to occur at a minimum cell length that is twice that of the newborn cell at any given growth rate (Donachie and Begg 1989a). During the period characterized by termination of DNA replication, completion of chromosome segregation, and initiation of septum formation, protein synthesis is required (Donachie and Begg 1989b/. Following initiation of septum formation, the cell division cycle continues until the daughter cells separate and again reach a specific $M_{i}$. The $\mathrm{Cmr}^{\mathrm{r}}$ selection has not identified any genes that appear to be defective in these later stages of the cell cycle.

\section{Conclusions}

Using several novel approaches to select gain-of-function mutants, we have identified nine $E$. coli mutants with increased ploidy. We believe that the mutants have increased ploidy because (1) they are resistant to camphor vapors; (2) they have an increased density in Percoll gradients; (3) they have at least a slight increase in the gene dosage of the lac operon; (4) they are no longer $\mathrm{Cmr}^{\mathrm{r}}$ in the presence of a defective $d n a A$ gene; and (5) for $m b r B, m b r C$, and $m b r D$, they are again $\mathrm{Cmr}^{\mathrm{r}}$ in the presence of a defective $d n a A$ gene and an $\mathrm{mh}^{-}$mutation. Our mutants define several new classes of cellcycle mutants in that they appear to act after DnaA-dependent initiation of DNA replication but before initiation of septum formation. Thus, the mbr mutants are likely contained within that part of the cell cycle where many different events must occur in a precisely timed fashion and very little information is known about how and where these events take place.

\section{Materials and methods \\ Bacteria and bacteriophages}

All of the strains used in this study are isogenic derivatives of $E$. coli $\mathrm{K}-12$ and are listed in Table 3. The dnaA204(Ts) $\mathrm{mbr}$ double mutants were constructed by $\mathrm{P} 1$ transduction from NT452 into NT596-NT620, selecting Kan ${ }^{\mathrm{r}}$. Marker rescue experiments were performed to confirm the presence of dnaA204(Ts). The rnh339:: cat mbr double mutants were constructed by P1 transduction from MIC1020 into NT596NT620, selecting Cam ${ }^{r}$. The triple mutants were constructed by Pl transduction from MIC1020 into the dnaA204(Ts) mbr double mutants. Plvir (lab stock) and T4gt7 (from K. Tilly) were used for generalized transductions. $\lambda$ NK561 and $\lambda$ NK1105 have been described (Way et al. 1984), as has the procedure for their use (Silhavy et al. 1984). Isogenic strains containing $\operatorname{mbr} A 15$, $m b r C 11, m b r C 18, m b r D 3$, and $m b r D 7$ and the various combinations of dnaA204(Ts) and $r n h 339::$ cat were constructed, and all of the experiments described were performed using them as well. The data are not shown; in all cases, they behave similiarly to the alleles presented.

\section{Media and reagents}

Liquid and solid media were as described (Silhavy et al. 1984), except for M56 minimal salts (Monod et al. 1951). Lactobionate plates contain M56 or M63 complete salts, 2.5\% lactobionate [free acid, $\sim \mathrm{pH} 7$ (Fluka Biochemika, Ronkonkoma, NY); the hemicalcium salt does not permit growth of E. coli] and $5 \mathrm{~mm}$ isopropyl-thio- $\beta$-D-galactoside (IPTG). $N, N$-methylnitrosoguanidine (NTG), 4,6-diamidino-2-phenylindole (DAPI), and poly-Llysine (m.w. 150,000-300,000) were purchased from Sigma (St. Louis, MO). Camphor ( \pm mixture) was purchased from Fluka Biochemika. 
Table 3. Bacterial strains

\begin{tabular}{|c|c|c|}
\hline Strain & Description & Source/construction \\
\hline BR4433 & dnaA204(Ts) & D. Chattoraj \\
\hline HS4004 & $\mathrm{F}^{-} \Delta$ (lac-pro)XIII strA relA metA rif thi & H. Shuman \\
\hline MC4100 & $\mathrm{F}^{-}$araD139 $\Delta(\arg F-1 a c)$ U169 rpsL150 relA1 flbB5301 deoC1 ptsF25 rbsR thi-1 & Casadaban $(1976)$ \\
\hline MIC1020 & $\mathrm{AB} 1157$ rnh339 :: cat & $\begin{array}{l}\text { Kanaya and Crouch } \\
(1984)\end{array}$ \\
\hline MG1655 & wild type & B. Bachmann \\
\hline NS1558 & dnaG(Ts) str ${ }^{r}$ leu thy $A$ & N. Sternberg \\
\hline NT1015 & MC4100 $\Delta$ malB15 & lab stock \\
\hline SFN135 & MC4100 $\arg G:: \operatorname{Tn} 10$ & Kiino and Silhavy (1984) \\
\hline SK2251 & $\mathrm{F}^{-}$gal-6 lacY1 malA1 xyl-7 his-1 leuB6 metB1 rpsL104 sup-59 zgi :: Tn10 T6r & Kiino and Silhavy (1984) \\
\hline RK4936 & $\begin{array}{l}\text { araD139 } \Delta \text { (argF-lac)205 flbB5301 gyrA219 non-9 relA1 rpsL150 metE70 } \\
\text { btuB :: Tn10 thi-1 deoC1 }\end{array}$ & B. Bachmann \\
\hline NT3 & $\mathrm{MC} 4100 \mathrm{lac}^{+}$ & $\begin{array}{l}\text { T4gt7(MG1655) into } \\
\text { MC4100 }\end{array}$ \\
\hline NT441 & NT3 proAB :: $\operatorname{Tn} 10 \mathrm{~F}^{\prime}$ lac-pro & $\begin{array}{l}F^{\prime} \text { mated in selecting } \\
\text { Pro }^{+}\end{array}$ \\
\hline NT452 & BR4433 zid2 :: $\Delta k a n$ & $\begin{array}{l}\Delta \text { kan }(\lambda N K 1105) \text { near } \\
\quad \text { dnaA204 }\end{array}$ \\
\hline NT596 & NT3 zgi4 :: Tn10 & $\begin{array}{l}\operatorname{Tn} 10(\lambda N K 561) \text { near } \\
\quad m b r A 4\end{array}$ \\
\hline NT597 & NT3 zij17 :: Tn10 &  \\
\hline NT603 & NT3 mbrD3 zij17 :: Tn10 & $\mathbf{C}^{\mathbf{a}}$ \\
\hline NT604 & NT3 mbrA4 zgi4 :: Tn10 & -a $^{\mathbf{a}}$ \\
\hline NT607 & NT3 mbrD7 zij17 :: Tn10 & - $^{\mathbf{a}}$ \\
\hline NT611 & NT3 mbrC11 zij17 :: Tn10 & - $^{\mathbf{a}}$ \\
\hline NT615 & NT3 mbrA15 zgi4 :: Tn10 & $-^{a}$ \\
\hline NT617 & NT3 mbrC17 zij17 :: Tn10 & - $^{a}$ \\
\hline NT618 & NT3 mbrC18 zii17 :: Tn10 & $-^{a}$ \\
\hline NT619 & NT3 mbrD19 zij17 :: Tn10 & - $^{a}$ \\
\hline NT620 & NT3 mbrB20 zij17 :: Tn10 & $-^{a}$ \\
\hline
\end{tabular}

${ }^{a} \mathrm{mbr}$ alleles were moved into NT3 from the original isolates by $\mathrm{P} 1$, using the linked $\operatorname{Tn} 10$.

\section{Genetic manipulations}

P1 transductions and isolation of Tn10 insertions near a gene have been described previously (Silhavy et al. 1984). Briefly, for the $m b r$ mutations, individual random pools of $\operatorname{Tn} 10$ transpositions were isolated in each of the mutant strains using $\lambda$ NK561. The pool sizes were $\sim 100,000$ Tn10 insertions. Subsequently, P1 was grown on each of the pools and used to transduce NT3 to $\mathrm{Tet}^{\mathrm{r}} \mathrm{Cmr}^{\mathrm{r}}$.

\section{NTG mutagenesis and camphor resistance}

NTG mutagenesis was carried out as described previously (Silhavy et al. 1984). Eight cultures were mutagenized, immediately split to 10 tubes each, and incubated in fresh media for $3-4 \mathrm{hr}$. The cells were serially diluted, plated at either $32^{\circ} \mathrm{C}$ or $37^{\circ} \mathrm{C}$, and incubated overnight. After colonies had formed, they were replica plated and incubated in the presence of camphor vapors. Only whole colonies that grew in the presence of camphor were retested, and no more than two colonies from any one culture were chosen. Of 129 mutants originally isolated, 29 remained stably $\mathrm{Cmr}^{\mathrm{r}}$. The levels of mutagenesis in the cultures were monitored by the appearance of $\mathrm{Lac}^{-}$colonies on lactose tetrazolium agar and $\mathrm{Gal}^{-}$colonies on galactose tetrazolium agar. In all cultures, the frequency of either $\mathrm{Lac}^{-}$or $\mathrm{Gal}^{-}$colonies was $1-3 \%$.

To expose cells to camphor vapors, $\sim 7-10$ grams of solid camphor was crushed in the lid of a petri plate. The cells were spread on the agar surface in the bottom of the plate and inverted over the camphor crystals. The plates were subsequently placed in a lidded plastic container and incubated at either 32 or $37^{\circ} \mathrm{C}$. At $32^{\circ} \mathrm{C}$, only a small amount of camphor is vaporized so that camphor-sensitive strains grow to form small colonies. At $37^{\circ} \mathrm{C}$, enough camphor is vaporized so that only $\mathrm{Cmr}^{\mathrm{r}}$ cells can grow. At temperatures above $39^{\circ} \mathrm{C}$, so much vaporization of the camphor takes place that no cells survive. The frequency of survival of LB-grown cells when exposed to camphor is $10^{-1}$ to $10^{-2}$ and that of glucose-grown cells is $10^{-3}$ to $10^{-4}$.

\section{Percoll gradients}

Percoll (Sigma, St. Louis, MO) was diluted to $72 \%$ in sterile water. Sodium chloride was added to a final concentration of 30 mM. Preformed Percoll gradients were prepared by adding 10.5 $\mathrm{ml}$ of Percoll solution to ultracentrifuge tubes and centrifuging in a type 40 rotor at $15,000 \mathrm{rpm}$ for $30 \mathrm{~min}$ at $4^{\circ} \mathrm{C}$. Preformed gradients were stored at $4^{\circ} \mathrm{C}$ for up to 1 week. To run the gradients, $1 \mathrm{ml}$ of a balanced growth culture was layered on top of the gradients and centrifuged in a Sorvall RC2B at $7000 \mathrm{rpm}$ for $20 \mathrm{~min}$ at $4^{\circ} \mathrm{C}$. The gradients were calibrated using color-coded density beads (Pharmacia LKB Biotechnology, Piscataway, NJ), and the position of the cell bands was measured in centimeters from the top of the tubes immediately upon removal of the gradients from the centrifuge. 


\section{DAPI staining and microscopy of cells}

Aliquots $(100 \mu \mathrm{l})$ of actively growing cells were mixed with $3 \mu \mathrm{l}$ of toluene and incubated at $37^{\circ} \mathrm{C}$ for $15 \mathrm{~min}$. Subsequently, $3 \mu \mathrm{l}$ of a $10 \mu \mathrm{g} / \mathrm{ml}$ DAPI solution (in water) was added, and the cells were incubated at room temperature for $30 \mathrm{~min}$. Slides were first washed with ethanol and wiped dry. Poly-L-lysine $(1 \%$ stock solution in saline; $20 \mu \mathrm{l}$ ) was placed on the cleaned slide and incubated at room temperature for $10 \mathrm{~min}$. Excess poly-Ilysine was removed, and the slides were washed in distilled water. A drop of stained cell suspension was placed in the polyL-lysine and allowed to settle for 5-10 $\mathrm{min}$. A drop of $1 \mu \mathrm{g} / \mathrm{ml}$ para-phenylenediamine (free base; Sigma) in $90 \%$ glycerol was placed on the cells, and a coverslip was placed over the suspension. After removing excess liquid and sealing the coverslip, slides were viewed under a $100 \times$ Neofluar objective on a Zeiss microscope using both UV and visible light. Photographs were taken with a $35-\mathrm{mm}$ camera attached to the microscope, using Kodak Tri-X pan black-and-white film. The film was developed using Diafine (Chicago, IL).

\section{Acknowledgments}

We thank Mark Willingham for his advice and instruction on microscopy procedures and S. Garges, M. Maurizi, T. Silhavy, V. Stout, M. Weickert, and M. Yarmolinsky for helpful discussions and critically reading the manuscript. N.J.T. is a fellow of the Jane Coffin Childs Memorial Fund for Medical Research. This investigation has been aided by a grant from The Jane Coffin Childs Memorial Fund for Medical Research.

The publication costs of this article were defrayed in part by payment of page charges. This article must therefore be hereby marked "advertisement" in accordance with 18 USC section 1734 solely to indicate this fact.

\section{References}

Atlung, T. 1981. Analysis of seven $d n a A$ suppressor loci in Escherichia coli. The initiation of DNA replication. ICNUCLA Symp. Mol. Cell. Biol. 21: 297-314.

Atlung, T., A. Lobner-Olesen, and F. G. Hansen. 1987. Overproduction of DnaA protein stimulates initiation of chromosome and minichromosome replication in Escherichia coli. Mol. Gen. Genet. 206: 51-59.

Bachmann, B. 1990. Linkage map of Escherichia coli K-12, edition 8. Microbiol. Rev. 54: 130-197.

Bauch, R. 1941. Experimentelle mutationslosung bei hefe und andern pilzen durch behandlung mit camphor, acenaphthene, und colchicine. Naturwissenschaften 29: $503-$ 504.

Bernander, R. and K. Nordstrom. 1990. Chromosome replication does not trigger cell division in E. coli. Cell 60: 365374.

Bi, E. and J. Lutkenhaus. 1990. FtsZ regulates frequency of cell division in Escherichia coli. I. Bacteriol. 172: 2765-2768.

Campbell, J.L. and N. Kleckner. 1990. E. coli oriC and dnaA gene promoter are sequestered from dam methyltransferase following the passage of the chromosomal replication fork. Cell 62: 967-979.

Casadaban, M.J. 1976. Transposition and fusion of the lac genes to selected promoters in Escherichia coli using bacteriophage lambda and Mu. I. Mol. Biol. 104: 541-555.

Cooper, S. and C.E. Helmstetter. 1968. Chromosome replication and the division cycle of Escherichia coli B/r. I. Mol. Biol. 31: 519-540.

deMassy, W.D., O. Fayet, and T. Kogoma. 1984. Multiple origin usage for DNA replication in $s d r(m h)$ mutants of Escherichia coli K-12. Initiation in the absence of oriC. I. Mol. Biol. 178: 227-236.

Donachie, W.D. 1968. Relationship between cell size and time of initiation of DNA replication. Nature 219: 1077-1079.

Donachie, W.D. and K.J. Begg. 1989a. Cell length, nucleoid separation and cell division of rod-shaped and spherical cells of Escherichia coli. J. Bacteriol. 171: 4633-4639.

- 1989b. Chromosome partition in Escherichia coli requires post replication protein synthesis. I. Bacteriol. 171: 5405-5409.

Donachie, W.D. and A.C. Robinson. 1987. Cell division: Parameter values and the process. In Escherichia coli and Salmonella typhimurium: Cellular and molecular biology (ed. F.C. Neidhardt, J.L. Ingraham, K.B. Low, B. Magasanik, M. Schaecter, and H.E. Umbarger), pp. 1578-1593. American Society for Microbiology, Washington, D.C.

Donachie, W.D., K.J. Begg, and N.F. Sullivan. 1984. Morphogenes of Escherichia coli. In Microbial development (ed. R. Losick and L. Shapiro), pp. 27-62. Cold Spring Harbor Laboratory, Cold Spring Harbor, New York.

Hansen, E.B., T. Atlung, F.G. Hansen, O. Skorgaard, and K. von Meyenburg. 1984. Fine structure genetic map and complementation analysis of mutations in the $d n a A$ gene of Escherichia coli. Mol. Gen. Genet. 196: 387-396.

Henson, J.M., B. Kopp, and P.L. Kuempel. 1984. Deletion of 60 kilobase pairs of DNA from the terC region of the chromosome of Escherichia coli. Mol. Gen. Genet. 193: 263-268.

Hiraga, S., H. Niki, T. Ogura, C. Ichinose, H. Mori, B. Ezaki, and A. Jaffe. 1989. Chromosomal partition in Escherichia coli: Novel mutants producing anucleate cells. J. Bacteriol. 171: 1489-1505.

Hirota, V., A. Ryter, and F. Jacob. 1968. Thermosensitive mutants of $E$. coli affected in the processes of DNA synthesis and cellular division. Cold Spring Harbor Symp. Quant. Biol. 33: 677-693.

Kanaya, S. and R.J. Crouch. 1984. The $r n h$ gene is essential for growth of Escherichia coli. Proc. Natl. Acad. Sci. 81: 34473451 .

Kiino, D.R. and T.J. Silhavy. 1984. Mutation prlF1 relieves the lethality associated with export of $\beta$-galactosidase hybrid proteins in Escherichia coli. J. Bacteriol. 158: 878-883.

Kogoma, T. and K.G. Lark. 1975. Characterization of the replication of Escherichia coli DNA in the absence of protein synthesis: Stable DNA replication. I. Mol. Biol. 94: 243256.

Kogoma, T. and K. von Meyenburg. 1983. The origin of replication, oriC and the $d n a A$ protein are dispensable in stable DNA replication $(s d r A)$ mutants of Escherichia coli $\mathrm{K}-12$. EMBO I. 2: 463-468.

Kuempel, P., S. Duerr, and N. Seeley. 1977. The terminus of the chromosome in Escherichia coli inhibits replication forks. Proc. Natl. Acad. Sci. 74: 3927-3931.

Kvetkas, M.J., R.E. Krisch, and M.R. Zelle. 1970. Genetic analysis of a large-cell, radiation-resistant strain of Escherichia coli. J. Bacteriol. 103: 393-399.

Langridge, J. 1969. Mutations conferring quantitative and qualitative increases in $\beta$-galactosidase activity in Escherichia coli. Mol. Gen. Genetics. 105: 74-83.

Lark, K.G. 1972. Evidence for direct involvement of RNA in the initiation of DNA replication in Escherichia coli $15 \mathrm{~T}^{-} . I$. Mol. Biol. 64: 47-60.

Lobner-Olesen, A., K. Skarstad, F.G. Hansen, K. von Meyenburg, and E. Boye. 1989. The DnaA protein determines the initiation mass of Escherichia coli K12. Cell. 57: 881-889.

Louarn, J., J. Patte, and J.M. Louarn. 1977. Evidence for a fixed 
termination site of chromosome replication in Escherichia coli K12. J. Mol. Biol. 115: 295-314.

Monod, J., G. Cohen-Bazire, and M. Cohn. 1951. Sur la biosynthese de la $\beta$-galactosidase (lactase) chez Escherichia coli. La specificite de l'induction. Biochim. Biophys. Acta. 7: $585-599$.

Mulder, E. and C.L. Woldringh. 1989. Actively replicating nucleoids influence positioning of division sites in Escherichia coli filaments forming cells lacking DNA. I. Bacteriol. 171: 4303-4314.

Ogawa, T., G.G. Pickett, T. Kogoma, and A. Kornberg. 1984 RNase $\mathrm{H}$ confers specificity in the dnaA-dependent initiation of replication at the unique origin of the Escherichia coli chromosome in vivo and in vitro. Proc. Natl. Acad. Sci. 81: $1040-1044$.

Ogden, G.B., M.J. Pratt, and M. Schaecter. 1988. The replicative origin of the $E$. coli chromosome binds to cell membranes only when hemimethylated. Cell 54: 127-135.

Ogg, J.E. and M.R. Zelle. 1957. Isolation and characterization of a large cell possibly polyploid strain of Escherichia coli. I. Bacteriol. 74: 477-484.

Rasmussen, K.V., T. Atlung, G. Kerszman, G.E. Hansen, and F.G. Hansen. 1983. Conditional change of DNA replication control in an RNA polymerase mutant of Escherichia coli. I. Bacteriol. 154: 443-451.

Sansome, E.R. 1946. Induction of "gigas" forms of Penicillium notatum by treatment with camphor vapour. Nature 157: 843

Silhavy, T.J., M.L. Berman, and L.W. Enquist. 1984. Experiments with gene fusions. Cold Spring Harbor Laboratory, Cold Spring Harbor, New York.

Tanaka, M., H. Ohmori, and S. Hiraga. 1983. A novel type of $E$. coli mutants with increased chromosomal copy number. Mol. Gen. Genet. 192: 51-60.

Von Meyenburg, K. and F.G. Hansen. 1987. Regulation of chromosome replication. In Escherichia coli and Salmonella typhimurium: Cellular and molecular biology (ed. F.C. Neidhardt, J.L. Ingraham, K.B. Low, B. Magasanik, M. Schaecter and H.E. Umbarger|, pp. 1555-1577. American Society for Microbiology, Washington D.C.

Way, J.C., M.S. Davis, D. Morisato, D.E. Roberts, and N. Kleckner. 1984. New Tn10 derivatives for transposon mutagenesis and for construction of $1 a c Z$ operon fusions by transposition. Gene 32: 369-379.

Woldringh, C.L. 1976. Morphological analysis of nuclear separation and cell division during the life cycle of Escherichia coli. I. Bacteriol. 125: 248-257.

Woldringh, C.L., J.S. Binnerts, and A. Mans. 1981. Variation in Escherichia coli buoyant density measured in percoll gradients. J. Bacteriol. 148: 58-63. 


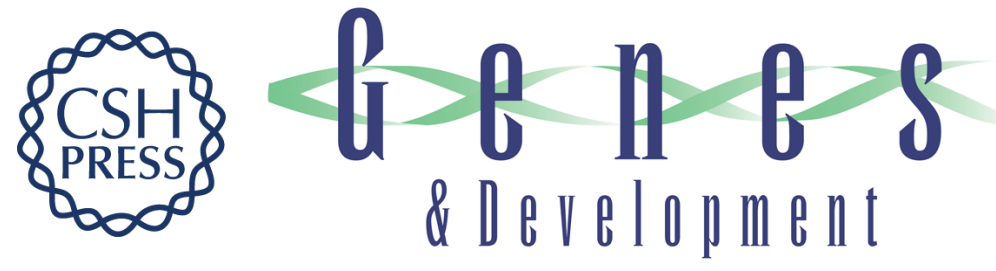

\section{On the bacterial cell cycle: Escherichia coli mutants with altered ploidy.}

N J Trun and S Gottesman

Genes Dev. 1990, 4:

Access the most recent version at doi:10.1101/gad.4.12a.2036

References This article cites 38 articles, 15 of which can be accessed free at:

http://genesdev.cshlp.org/content/4/12a/2036.full.html\#ref-list-1

License

Email Alerting

Service

Receive free email alerts when new articles cite this article - sign up in the box at the top right corner of the article or click here. 